\title{
Pre-exposure to drought increases the resistance of tropical forest soil bacterial communities to extended drought
}

\author{
Nicholas J Bouskill ${ }^{1}$, Hsiao Chien Lim ${ }^{1}$, Sharon Borglin ${ }^{1}$, Rohit Salve ${ }^{2}$, Tana E Wood ${ }^{3,4}$, \\ Whendee L Silver ${ }^{3}$ and Eoin L Brodie ${ }^{1}$ \\ ${ }^{1}$ Ecology Department, Earth Sciences Division, Lawrence Berkeley National Laboratory, Berkeley, CA, USA; \\ ${ }^{2}$ Hydrology Department, Lawrence Berkeley National Laboratory, Berkeley, CA, USA; ${ }^{3}$ Department of \\ Environmental Science, Policy and Management, University of California-Berkeley, Berkeley, CA, USA and \\ ${ }^{4}$ International institute of Tropical Forestry, USDA Forest Service, Rio Piedras, PR, USA
}

\begin{abstract}
Global climate models project a decrease in the magnitude of precipitation in tropical regions. Changes in rainfall patterns have important implications for the moisture content and redox status of tropical soils, yet little is known about how these changes may affect microbial community structure. Specifically, does exposure to prior stress confer increased resistance to subsequent perturbation? Here we reduced the quantity of precipitation throughfall to tropical forest soils in the Luquillo Mountains, Puerto Rico. Treatments included newly established throughfall exclusion plots (de novo excluded), plots undergoing reduction for a second time (pre-excluded) and ambient control plots. Ten months of throughfall exclusion led to a small but statistically significant decline in soil water potential and bacterial populations clearly adapted to increased osmotic stress. Although the water potential decline was small and microbial biomass did not change, phylogenetic diversity in the de novo-excluded plots decreased by $\sim 40 \%$ compared with the control plots, yet pre-excluded plots showed no significant change. On the other hand, the relative abundances of bacterial taxa in both the de novo-excluded and pre-excluded plots changed significantly with throughfall exclusion compared with control plots. Changes in bacterial community structure could be explained by changes in soil pore water chemistry and suggested changes in soil redox. Soluble iron declined in treatment plots and was correlated with decreased soluble phosphorus concentrations, which may have significant implications for microbial productivity in these P-limited systems.
\end{abstract}

The ISME Journal (2013) 7, 384-394; doi:10.1038/ismej.2012.113; published online 15 November 2012

Subject Category: microbial ecology and functional diversity of natural habitats

Keywords: resistance; pyrosequencing; drought effects; temporal

\section{Introduction}

Humid tropical forests are globally important carbon (C) reservoirs (Jobbágy and Jackson, 2000), storing $\sim 25 \%$ of terrestrial organic C (Pan et al., 2011). The warm humid conditions in these forests lead to high rates of $\mathrm{C}$ fixation via net primary productivity (Grace et al., 2001). Conversely, tropical soils have high rates of organic matter decomposition and soil respiration (Ross, 1993). Rates of organic matter decomposition are dependent on several factors, most notably soil moisture and

Correspondence: NJ Bouskill or EL Brodie, Ecology Department, Earth Sciences Division, Lawrence Berkeley National Laboratory, 70A-3317, Berkeley, CA 94702, USA.

E-mail: njbouskill@lbl.gov or elbrodie@lbl.gov

Received 2 April 2012; revised 30 July 2012; accepted 14 August 2012; published online 15 November 2012 redox potential, soil nutrient availability and the phylogenetic and functional constraints of the microbial community (Vitousek and Howarth, 1991; Cleveland et al., 2006; Schmidt et al., 2011). Soil moisture has a significant role in determining rates of decomposition by constraining microbial community activity via two primary mechanisms that lie at opposite ends of an activity bell curve (Supplementary Figure S1). In one instance, high soil moisture reduces gaseous diffusion into and out of the soil leading to oxygen limitation (Liptzin et al., 2011). Low soil moisture may constrain substrate diffusion and impart physiological stress on microbial communities.

Multiple climate models project large-scale changes in annual rainfall regimes of biomes within lowlatitude convective margins, including Central America and Caribbean regions (Neelin et al., 2006; Trenberth et al., 2007). These locations are 
likely to experience changes in the magnitude of rainfall (Giorgi and $\mathrm{Bi}, 2005$ ), with increased drought and longer dry periods (Easterling et al., 2000; Meehl et al., 2006). These changes may have significant implications for biogeochemical cycling due to tight coupling between soil moisture status, redox conditions, nutrient availability and microbial activity. Indeed, previous studies have demonstrated the sensitivity of tropical forest trace gas flux to changes in soil moisture (Vasconcelos et al., 2004; Holtgrieve et al., 2006), although, the magnitude of trace gas flux, as well as the direction of that flux is variable (Davidson et al., 2004, 2008; Metcalfe et al., 2007; Cleveland et al., 2010; Wood and Silver, 2012).

Soil moisture status is also a well-known regulator of microbial community diversity and function (Fierer et al., 2003; Carbone et al., 2011; Evans and Wallenstein, 2011; Hueso et al., 2012), yet to our knowledge there have been no attempts to evaluate the mechanistic basis by which microbial community diversity and function might respond to changes in soil moisture in a tropical forest. Under decreased rainfall, soil water potential $(\Psi)$ declines, solute concentrations increase and pore connectivity is reduced, imparting physical and physiological stresses on individual microbes and whole communities (Stark and Firestone, 1995; Schimel et al., 2007; Chowdhury et al., 2011) that can significantly alter an ecosystem's function (for example, Zak et al., 2003; Carney et al., 2007). Community response is determined by the severity of drought and the tolerance of different taxa to changes in $\Psi$. Because microbial communities are characterized by high rates of growth and community turnover (Prosser et al., 2007), prolonged drought may bring about shifts in community structure, selecting for taxa capable of tolerating the perturbation.

The degree to which community structure can be perturbed by environmental fluctuations, and hence, their resistance to perturbations, may be influenced by climate history. For example, microbes in temperate ecosystems can experience large inter- and intra-annual variability in soil moisture that selects for communities acclimated to rapid changes in $\Psi$ (for example, Fierer et al., 2003; Landesman and Digton, 2010). Therefore, the phylogenetic and functional diversity of microbial communities within many temperate regions might not be greatly perturbed if changes to seasonal precipitation fall within the limits of that region's seasonal variability (Landesman and Digton, 2010). On the other hand, the adaptive capacity of communities acclimated to generally high soil moisture, such as the humid tropical rainforests, is still unknown. Microbial communities within humid tropical rainforest soil may be more likely to adapt to rapid changes in oxygen or redox conditions (Silver et al., 1999, 2005; Pett-Ridge and Firestone, 2005; DeAngelis et al., 2011), than changes in osmotic potential. Therefore, while the disruption in rainfall patterns might be smaller in magnitude at the convective margins, the overall effect on microbial communities may be greater due to a lack of acclimation in ancestral populations to $\Psi$ stress (for example, Leibler and Kussell, 2010).

Microbial populations are known to develop resistance to repeated perturbations (Bressan et al., 2008; Allison et al., 2010; Wallenstein and Hall, 2012). However, it is not clear whether selection for resistant taxa results from single or multiple perturbation events. Here we examine whether bacterial community resistance can develop rapidly by following a 10-month throughfall exclusion experiment at a Long-Term Ecological Research site in Puerto Rico. Throughfall precipitation (that is, the precipitation falling through the forest canopy) was excluded in five plots that previously experienced short-term (3-month) throughfall exclusion (Wood and Silver, 2012) as well as five additional plots that experienced throughfall exclusion for the first time.

We measured in situ bacterial diversity and microbial biomass across treatments and also examined whether throughfall exclusion selected for bacteria adapted to higher solute concentrations. This study tests two hypotheses: (1) Microbial communities within an ecosystem with relatively infrequent drought will be sensitive to small changes in $\Psi$ and consequentially show large changes to community composition and decreased diversity. (2) Endemic bacteria in these soil plots lack the capacity to adapt to environmental change precluding the development of community resistance to a departure in long-term environmental conditions. The previous short-term exposure to drought will therefore not enhance resistance to repeated drought.

\section{Materials and methods}

Site description, throughfall exclusion, soil sampling and chemical analysis

This study was conducted in a humid tropical forest in the Bisley Research Watershed of the Luquillo Experimental Forest in Puerto Rico ( $\sim 350 \mathrm{~m}$ a.s.l; $18^{\circ} 18 \mathrm{~N},-65^{\circ} 50 \mathrm{~W}$; average rainfall $\sim 3500 \mathrm{~mm}$ per year with $\sim 200 \mathrm{~mm}$ per month). A detailed classification of these soils has been published previously (Dubinsky et al., 2010). Throughfall was excluded with clear, corrugated plastic panels $\left(\sim 1.6 \mathrm{~m}^{2}\right)$ mounted $1 \mathrm{~m}$ above the forest floor at a $17^{\circ}$ angle. Ten plots were randomly established between tree stands in June 2008, and five of these excluded for a period of 3 months before the shelters were removed and ambient throughfall resumed (in the present study these plots are termed pre-excluded). The following year (June, 2009), the shelters were replaced over these original treatment plots and five new exclusion plots were established (termed de novo in the present study), the remaining 5 plots were never sheltered and served as control plots. The plots were not trenched to minimize soil 
disturbance and allow root interaction and leaf litter was manually replaced from the top of the shelters back to the soil beneath every 4 to 7 days. Soil samples $(\sim 5-10 \mathrm{~g})$ were taken at the outset of the study and again at 3 and 10 months after throughfall shelters were erected. Soil water was extracted from fresh soil samples and analyzed for various parameters, including $\mathrm{pH}$, conductivity, cation and anion concentrations, whereas soils were analyzed for $\mathrm{pH}$, moisture content and water potential and microbial biomass by PLFA analysis. A full description of soil sampling and chemical analysis appears in the Supplementary Material. Additional details on the study site and throughfall shelter construction can be found in Wood and Silver (2012).

\section{DNA extraction and barcoded pyrosequencing}

Total nucleic acids were extracted from $0.5 \mathrm{~g}$ of soil per replicate according to the cetyl trimethylammonium bromide/bead-beating-based protocol described in Ivanov et al. (2009). Soil DNA samples were normalized to $10 \mathrm{ng} \mu \mathrm{l}^{-1}$ before PCR. Samples were amplified using a universal primer pair targeting the SSU rRNA V9 region and PCR reactions were performed using Takara Ex Taq hot-start polymerase (Takara, Madison, WI, USA). The barcoded PCR reactions were analyzed for quantity and quality (using a 7500 DNA chip on a Bioanalyzer 2100, Agilent Technologies, Santa Clara, CA, USA). Sequencing libraries were created using the SV emuPCR kit (Lib-A, Roche, Indianapolis, IN, USA) and sequencing on a GS-FLX sequencer (Roche) at the Veterans Medical Research Foundation, La Jolla, CA, USA. Further details of DNA extraction, 16S rRNA PCR and preparation for pyrosequencing can be found in the Supplementary Materials.

\section{Pyrosequencing data processing and statistical analysis}

Raw 454 sequences were uploaded, denoised and processed using the Quantitative Insights Into Microbial Ecology pipeline (Caporaso et al., 2010). Quality filtering, barcode reassignment, processing of pyrosequencing data and basic ordination statistics are described in the Supplementary Material. Soil chemistry data was tested for normality and log transformed where necessary. The effects of experimental drought on soil chemistry and enzyme activity was assessed comparing the control with treatment plots using two-way ANOVA, whereas the relationship between soil water chemistry and changes in either soil moisture or $\Psi$ was further quantified using a regression analysis (Draper and Smith, 1998). Variance partitioning approaches (permutational multivariate analysis and constrained principal components analysis) were applied to explain any phylogenetic changes as a function of treatment. Sequences from this study were submitted to MG-RAST under the Accession number ID:1005. Full details can be found in the Supplementary Material.

\section{Results}

Soil water content and chemistry

Soil water chemistry was significantly altered in both the pre-excluded and de novo-excluded soils when compared with the unsheltered control soils following 10 months of throughfall exclusion. Measured values of $\Psi$, gravimetric soil moisture, dissolved organic carbon (DOC), electrical conductivity (EC), pH, Fe, Al, $\mathrm{Na}$ and $\mathrm{K}$ concentrations are given in Table 1 (and Supplementary Table S1). The strongest treatment effect was observed in the de novo-excluded plots where $\mathrm{Na}$ concentrations were significantly higher $(P=0.01)$ than that of the controls. Conversely, $\Psi$, soil moisture, $\mathrm{Fe}, \mathrm{Al}$ and $\mathrm{P}$ were significantly higher in the control plots than the de novo-excluded plots (all $P<0.05)$. Soil pore water from the pre-excluded plots also differed from the control plots and showed similar trends to that of the de novo-excluded plots; however, these effects were not as pronounced as for the de novo-excluded plots. $\Psi, \mathrm{P}$ and $\mathrm{Fe}$ and $\mathrm{Al}$ concentrations were significantly higher in the control than in the pre-excluded soils $(P<0.05)$. Soil moisture was higher and $\mathrm{Na}$ concentrations lower in the control than in the pre-excluded soils, however, these trends were not statistically significant. The pre-excluded soils also differed from the de novo-excluded soils with significantly higher soil $\mathrm{pH}(P=0.046)$ and lower Na concentrations $(P=0.04)$.

Throughfall exclusion had no significant effect on soil water DOC concentrations, which ranged from 6.46 to $6.33 \mathrm{mg} \mathrm{l}^{-1}(P=0.44)$. Ammonium concentrations in the throughfall-excluded soils increased $27 \%$ and $32 \%$ relative to the control (de novoexcluded and pre-excluded, respectively) and soil nitrate concentrations were significantly higher in the de novo-excluded soils (two-way ANOVA, $P=0.012$ ). Soil water $\mathrm{Fe}$ and $\mathrm{Al}$ concentrations were significantly elevated in control soils compared with the treatment soils (de novo-excluded and pre-excluded; $P=0.001$ ) and were correlated positively with phosphate concentrations (all plots; $r^{2}=0.84 ; P=0.002$ ). Furthermore, across all plots a number of edaphic variables were significantly correlated with soil moisture; for example, solute concentrations $\left(\mathrm{Na}^{+}\right.$and $\mathrm{K}^{+}$) were both negatively correlated with soil moisture $\left(r^{2}=-0.83\left(\mathrm{Na}^{+}\right)\right.$; - $0.73\left(\mathrm{~K}^{+}\right), P$-value $\left.<0.05\right)$.

\section{Community diversity}

The indigenous microbial community of the Luquillo Experimental Forest soil was largely dominated by members of the Acidobacteria, Alphaproteobacteria and Planctomycetes, with slightly lower abundances of Actinobacteria and Gammaproteobacteria (Supplementary Figure S2). Before 
the placement of shelters, the genetic diversity (Faith's PD) of the soil communities was not different (Figure 1a). Furthermore, Chao1 estimates of species richness showed no significant difference between treatment and control soils (1589 \pm 603 ; $1618 \pm 752$; $1578 \pm 230$ for the control, pre- and de novo-excluded respectively).

There was no significant difference in the biomass of the soil plots over time, or between the treatment and control soils (Supplementary Figure S3), however, sampling at both three and ten months of throughfall exclusion found significant changes in the community composition (diversity and abundance) of the de novo-excluded soils compared with the control soils. Following 3 months of throughfall exclusion, the community composition of the de novo-excluded soils diverged from that of the control soils to form two distinct clusters (Figure 2b). Chao1 richness estimates for the de novo-excluded soils (average \pm s.d.; $1909 \pm 311$ ) were lower than the control soils $(2310 \pm 318)$ and significantly lower than the pre-excluded soils (2522 $\pm 230, P=0.005)$. This divergence could be explained by higher relative abundance of members of the Alphaproteobacteria (Rhodospirillales), Acidobacteria (Groups 1, 3 and 13) and the Planctomycetes (Isosphaera and Gemmata) (Supplementary Figure S5) in the de novo-excluded soils compared with the control soils. Dissimilarity of control and de novo-excluded soils was even more distinct at 10 months (Figure 2c) particularly when the relative abundance of taxa is not considered (Figure 2f).

By contrast, the diversity of the pre-excluded soils remained significantly higher than the de novoexcluded soils throughout the course of the treatment (Figure 2c, $P=0.008$ (after 3 months), $P=0.0002$ (after 10 months)), with taxon richness and diversity similar to that of the control soils (Figures 1c and 2f). However, a weighted analysis found that as perturbation continued, communities within the pre-excluded soils became more distinct from the controls soils and more similar to the de novo-excluded soils (Figure 2c). In this instance, the influence of eliminated throughfall on the preexcluded soils manifested as changes in the relative abundance of organisms, but not as decreased diversity (Figure 1c).

At the phylum level, changes in the community composition between the control and the excluded soils were mostly attributable to elevated relative abundance of Planctomycetes, Actinobacteria and some Proteobacteria in the treatment soils, with concurrent reduction of some Acidobacteria, Bacteroidetes and Firmicutes (Supplementary Figure S6). At finer phylogenetic resolution (that is, the family and genus level), the taxa in higher abundance under throughfall exclusion were remarkably similar in the pre-excluded and de novo-excluded treatments (and in the de novo treatments at the 3 - and 10-month sampling points), suggesting that, over time, organisms that are adapted to more arid 

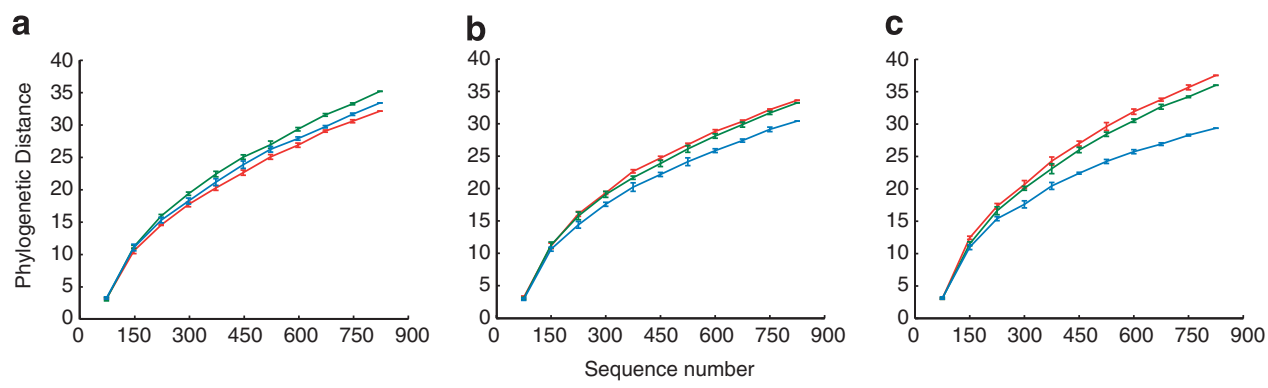

Control plots

De Novo plots

Figure 1 Phylogenetic distance for control and rainfall exclusion plots over time: (a) June 2009; (b) August 2009; (c) April 2010. The curves represent the average ( \pm s.d.) of the Faith's PD statistic over time.
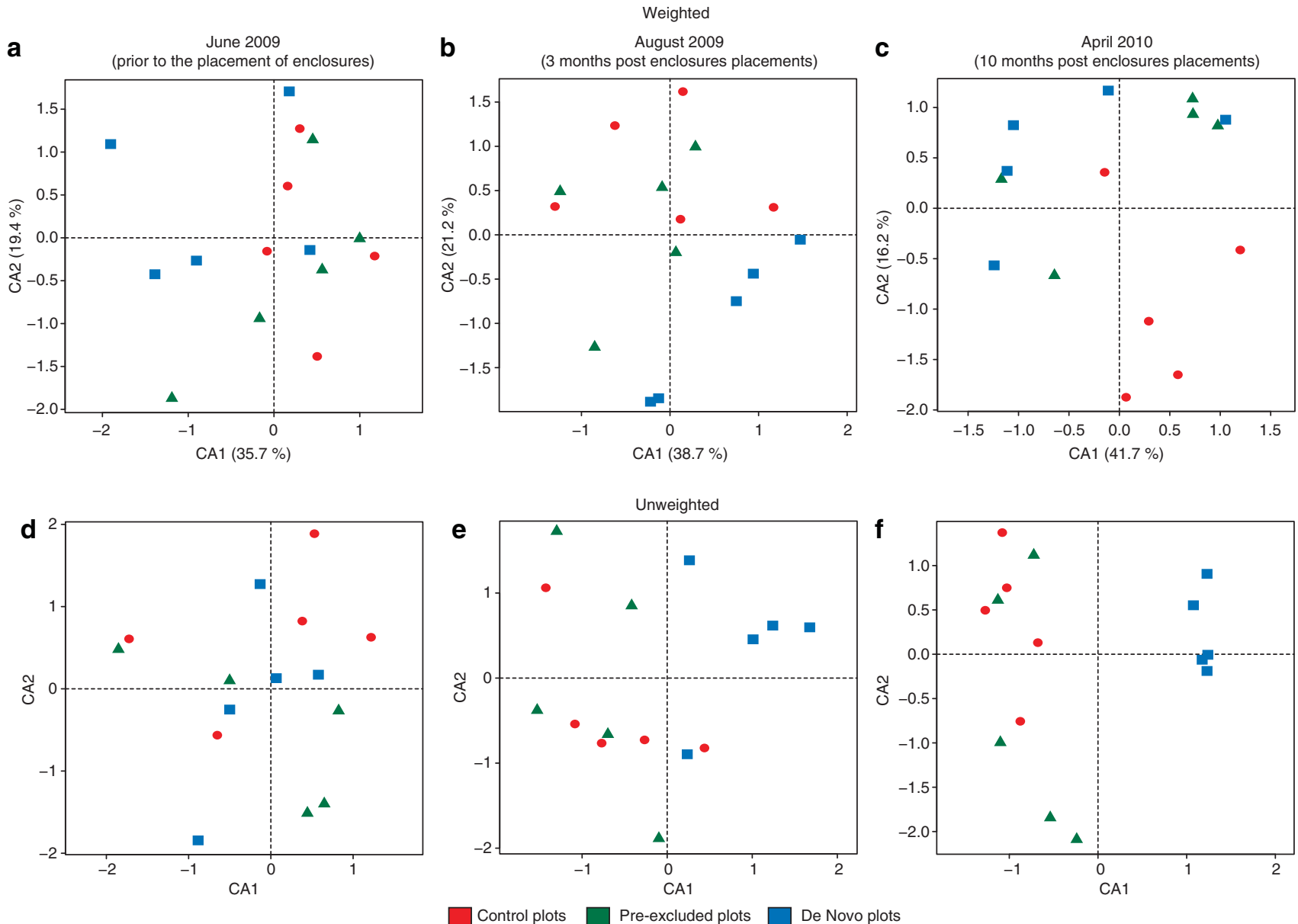

Figure 2 (a) Weighted and (b) unweighted correspondence analysis of the individual control and treatment plots over time: (a, d) June 2009, (b, e) August 2009 and (c, f) April 2010. The CA plots depict the ordination of weighted unifrac distance matrices showing the distinction of rainfall exclusion plots from the control plots following 10 months of the exclusion. Site markers represent replicates within the different treatments.

conditions become numerically more abundant (Figure 3). The Planctomycetes genera Gemmata and Isosphaera increased notably under throughfall exclusion in both treatments, as did the alphaproteobacterial Rhizobiales and Rhodospirillales (Figure 3). The Actinobacteria also increased in abundance (confirmed by quantitative PCR;
Supplementary Figure S6) in treatment plots and this was mainly attributed to members of the Actinomycetales, although Rubrobacterales were also more prominent under throughfall exclusion. Finally, despite an overall decline in Acidobacteria at the phylum level, two groups, 1 and 3, increased significantly in the de novo-excluded soils and were 


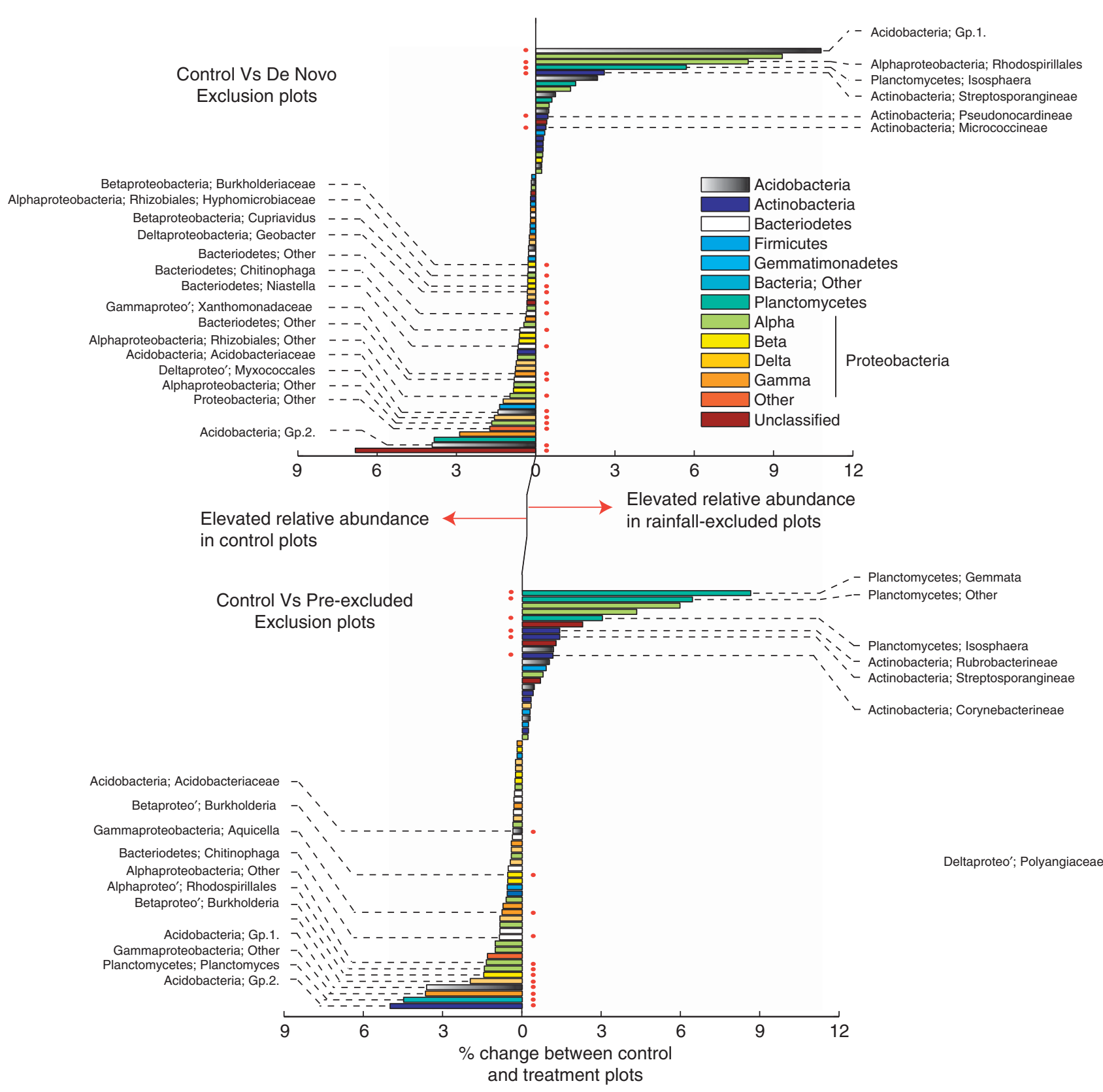

Figure 3 Differences in the relative abundance of different taxa between the treatment and control plots following 10 months throughfall exclusion. The different bars are colored by phylum (with the exception of the Proteobacteria that are differentiated at the class level). The data is drawn from the OTU tables and the labels identify the most prominent taxa down to highest taxonomic level available. Bars are the average of five replicate plot/treatment. Significant differences (ANOVA, $P \leqslant 0.05$ ) between the two groups are signified using red dots adjacent to a given bar.

large contributors to community structure differences at both the 3- and 10-month time points (see Figure 3 and Supplementary Figure S5). Despite increasing relative abundance of Rhizobiales and Rhodospirillales, the reduction in diversity of the de novo-excluded treatment communities could mainly be attributed to the loss of Proteobacteria (in particular other Alphaproteobacteria) and Acidobacteria (Supplementary Figure S7). The Acidobacteria Group 1 and the Rhodospirillales show contrasting responses to treatment in the de novoexcluded compared with the pre-excluded soils, and increased in relative abundance in the de novoexcluded soils. However, given that the highest taxonomic resolution achievable was at the genus level, it is possible that the reason for these divergent results is rooted in greater diversity at the species level.

To examine the relationship between treatments and edaphic properties toward community dissimilarity, 
the following variables were used in a permutational multivariate test (Adonis): (1) treatment (control or exclusion); (2) $\Psi$, Na concentrations and the interaction between these variables (Supplementary Table S2). The analysis demonstrated a significant effect of changing physicochemical properties of the soil water (Supplementary Table S2), Na concentrations $(F=2.88 ; P=0.02)$ and the interaction between Na concentrations and $\Psi(F=3.21 ; P=0.01)$.

A principal components analysis was used to elucidate the genotype-environment relationships and determine which edaphic factors are important in driving the dissimilarity between individual samples of the different treatments. After 10 months, the treatment communities separated from the control soils across the primary axis (Figure 4); with the de novo-excluded soils forming a more coherent cluster than the pre-excluded soils. The de novoexclusion plots showed a positive relationship with changes in soil chemistry that could be attributed to a reduction in throughfall, that is, elevated pore water solute concentrations (for example, $\mathrm{Na}$ ) and a decrease in $\Psi$ (Figure 4). The community structure in these soils was negatively correlated with soil $\mathrm{pH}$ and the concentration of $\mathrm{Fe}$ and $\mathrm{P}$. This was also true for de novo soils following 3 months of throughfall exclusion (Supplementary Figure S8). The communities in the majority of the pre-excluded soils showed a positive correlation with $\mathrm{NO}_{3}$ and $\mathrm{Ca}$ concentration and correlated negatively with gravimetric soil water content, which declined over the course of the experiment.

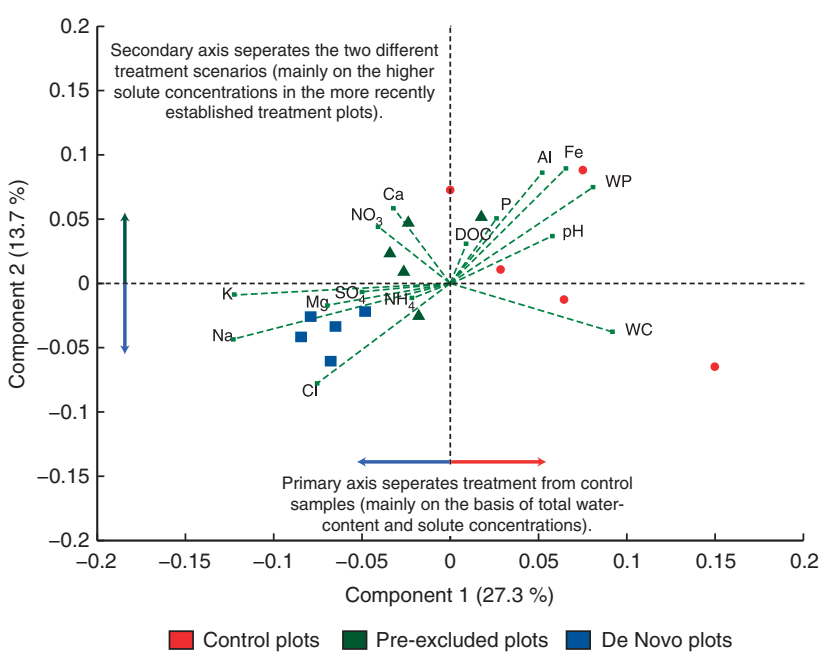

Figure 4 Principal components analysis detailing the relationship between plot community composition and edaphic factors following 10 months of rainfall exclusion. The principal components analysis plot is based on correlations between biological and physicochemical variables. Biological site markers are the same as that for Figure 2. Abbreviated physicochemical variables: $\mathrm{Ca}$, calcium; Cl, chloride; DOC, dissolved organic carbon; Fe, iron; $\mathrm{K}$, potassium; Mg, magnesium; Mo, molybdenum; Na, sodium; $\mathrm{NH}_{4}$, ammonium; $\mathrm{NO}_{3}$, nitrate; $\mathrm{P}$, phosphate; $\mathrm{SO}_{4}$, sulfate; $\Psi$, water potential; $\mathrm{WC}$, water content.

\section{Discussion}

There are many reasons to expect that tropical microbial communities, like temperate communities (Landesman and Digton, 2010), would contain a wide adaptive capacity to respond to perturbation. Microbial communities in some tropical soils are characterized by large population numbers $\left(\sim 10^{11}\right.$ $10^{12}$ cells per g soil, Dubinsky et al., 2010) maintaining an extensive reservoir of physiological and functional plasticity that can adapt to a range of optimal environmental conditions. In addition, microbes harbor multiple mechanisms to directly respond to changes in localized environmental conditions, which in the case of drying soil, include the upregulation of stress pathways to protect macromolecular structure (Walsh, 2000) and, if necessary, dormancy (Jones and Lennon, 2010). Conversely, theoretical studies in general ecology have demonstrated that the severity of risk of climate change is dependent not only on the rate of change of a given parameter (for example, temperature or drought onset), but also on the physiological sensitivity and adaptive capacity of a population to buffer the effects of change (Deutsch et al., 2008; Huey et al., 2009). Consequentially, temperate organisms generally have a broad tolerance to environmental change built around large seasonal fluctuations in temperature and rainfall compared with tropical organisms that are acclimated to low seasonal variability and living close their environmental optimum (Deutsch et al., 2008; Bonebrake and Mastrandrea, 2010).

In the present study, we demonstrate that the microbial community structure in a humid tropical forest was profoundly affected by changes in soil chemistry accompanying throughfall reduction, supporting the first hypothesis that humid tropical environments are sensitive to changes in rainfall. This degree of sensitivity, however, is greatly dependent on previous exposure to perturbation and the temporal extent of throughfall exclusion. Evidence for this comes from the resistance to repeat exposure of communities subject to prior perturbation (that is, the pre-excluded soils). These soil plots showed no significant reduction in phylogenetic diversity, whereas diversity declined in the de novoexcluded soils by $\sim 40 \%$. There was, however, a compositional shift in the pre-excluded communities following repeat perturbation, likely attributable to elevated relative abundance of drought tolerant organisms.

On a qualitative scale, the pre-excluded soil plots appear more resistant to future perturbation: although tolerant taxa are selected for in both treatment plots and subsequently increase in relative abundance (see discussion below), differences were noted in the response of the putatively sensitive taxa to the effects of treatment (that is, decreasing $\Psi$ and increasing osmotic potential). The de novo-excluded plots maintain lower diversity 
than both the pre-excluded and the control plots, indicating an effect of exclusion on putatively sensitive taxa that are absent in the pre-excluded plots. Both treatments (pre-excluded and de novoexcluded) select for organisms (Streptomycetes spp.) that are adapted to grow at higher $\mathrm{NaCl}$ concentrations than the control plots (Supplementary Figure S4) indicating a similar extent of adaptation. Furthermore, the phyla responsible for these compositional differences between the treatment plots and the control plots were similar in the de novoand pre-excluded plots (for example, Actinobacteria and Planctomycetes) (Figure 3 and Supplementary Figure S6); yet the magnitude of the differences was greater in the de novo-excluded plots. It would follow that pre-exposure to perturbation selects for tolerant taxa, but may also condition putatively sensitive taxa to repeat perturbation.

Given that the initial de novo-excluded and preexcluded communities (June 2009) were so similar, the fact that one short period of perturbation could condition the pre-excluded communities is surprising. However, microbial communities are known to adapt rapidly to fluctuating environmental conditions (for example, Schimel et al., 2007; DeAngelis et al., 2011) and resistance has been recorded for soil communities subject to repeat perturbation (Wertz et al., 2007; Chaer et al., 2009; Bowen et al., 2011; Evans and Wallenstein, 2011). Although identifying the mechanisms underlying this pre-conditioning to future disturbances requires further investigation, our second hypothesis, that short-term throughfall exclusion treatment is insufficient to allow development of resistance, did not hold for this forest.

Eliminated throughfall was accompanied by changes in soil chemistry that likely had a large role in shaping microbial community composition. Previous studies examining changes in soil trace gas flux under decreased throughfall have reported significant responses of soil respiration to changes in soil chemistry (Cleveland et al., 2010; Wood and Silver, 2012). Our conceptual model depicting microbial activity along a gradient of soil moisture (Supplementary Figure S1) would predict that under water-saturated conditions microbial respiration is limited by a lack of $\mathrm{O}_{2}$ diffusion into the soil and the formation of anoxic regions (Liptzin et al., 2011). At the other end of the gradient, retreating water films impart substrate limitation on microbial activity through reduced diffusion (Stark and Firestone, 1995). In addition, and in the same region of the curve, physiological stress, imparted as soils dry and pore water solute concentrations increase, can also have a large role in shaping community activity and composition. In the present study, it is likely that treatment soils can be placed at the intersection between substrate limitation and physiological stresses (Supplementary Figure S1). Constrained ordination analysis (Figure 4) suggests that physiological stress resulting from decreased $\Psi$ and elevated solute concentrations are more important than C substrate limitation in this system. In support of this, throughfall-excluded plots showed an elevated relative abundance of a number of bacteria (for example, Actinomycetales) that could be considered drought tolerant, while also supporting bacteria that exhibit a greater tolerance of osmotic stress and perhaps a preference for elevated solute concentrations (Supplementary Figure S4).

We also observed a phylogenetic signal to the changes in community composition under altered soil moisture, which seemingly selected for Actinobacteria and Planctomycetes, both of which showed elevated abundance under throughfall exclusion. Actinobacteria are a widely distributed group with a well-studied ecology (Goodfellow and Williams, 1983) show adaptive resistance to drought (Davet, 2004) and reach high abundance in arid soils (Okoro et al., 2009). Actinobacteria (specifically Streptomycetes) have been demonstrated to grow at low osmotic potential (Klevenskaya, 1960), and also increase in proportional abundance within dry soil (Bacher et al., 2010). In addition, although the spores of Actinobacteria are known to survive extended periods of desiccation at high temperatures (Williams et al., 1972), it is also likely that they are also capable of growth during periods of prolonged drought (Williams et al., 1972). Furthermore, the ecological distribution of Actinobacteria displays a negative trend with soil moisture content and tend to dominate arid environments (for example, Chanal et al., 2006), therefore, it is perhaps not surprising that the changes in soil pore water chemistry recorded in this study favor elevated relative abundance of Actinobacteria. On the other hand, a lack of cultured representatives means that little is known about the ecophysiology of the Planctomycetes. However, they are likely to be important players in the $\mathrm{C}$ and $\mathrm{N}$ cycle (Fuerst and Sagulenko, 2011), and are widely distributed across different ecosystems with high abundance in arid soils, such as the Atacama Desert topsoil (Drees et al., 2006). Based on these observations and the data herein, it is possible that the Planctomycetes maintain adaptive traits that allow the group to increase competitiveness under low $\Psi$. However, previous work (for example, Bacher et al., 2010) and the present study (Supplementary Figure S6) also demonstrate Planctomycetes to be sensitive to changes in soil water content. Therefore, further work is required to understand the mechanism by which Planctomycetes adapt to their environment.

Throughfall exclusion had a large effect on soil water content and solute concentration, which accounts for the largest statistical variance across the microbial community dataset (component 1 in Figure 4). In addition, exclusion affected nutrient cycling and may have had an effect on soil mineralogy, both intimately intertwined with the microbial components of soil. Highly weathered tropical forest soils are generally assumed to have low available P concentrations (Walkers and Syers, 
1976; Vitousek and Sanford, 1986) with P limitation compounded by the high sorbtive capacity of Ferich primary (Geothite) and Al-rich secondary (kaolinite) minerals. Our data show that $\mathrm{P}$ availability declined in soils under throughfall exclusion and a likely explanation for this is the changes in $\mathrm{Fe}$ redox cycling that occur as soils become more oxic. The oxidation of $\mathrm{Fe}(\mathrm{II})$ to $\mathrm{Fe}(\mathrm{III})$ will result in increased sorption of soluble P (Reed et al., 2011), whereas previously sorbed $\mathrm{P}$ is no longer released through microbially catalyzed reductive dissolution of Fe-bearing minerals (Chacon et al., 2006; Liptzin and Silver, 2009; Wood and Silver, 2012). Our data support this rationale; we recorded a significant decrease in soluble $\mathrm{Fe}$ and $\mathrm{Al}$ concentrations between control and treatment plots and a strong positive correlation with $\mathrm{P}$ concentrations (preexcluded and de novo-excluded; $r^{2}=0.85$ ). This is significant as $\mathrm{P}$ availability is an established driver of microbial community diversity and activity within aquatic and terrestrial ecosystems (Jones and Lennon, 2010; Reed et al., 2011; Townsend et al., 2011). Additionally, a decline in available $\mathrm{P}$ was significantly correlated with a decline in soil respiration in a previous study at this site (Wood and Silver, 2012) and may also be an important contributing factor to the changes in community composition recorded here. These results stimulate a number of important questions: does greater $\mathrm{P}$ limitation further constrain microbial activity and, over time, is it of greater importance than the physiological stress brought on by elevated solute concentrations, which can result in rapid adaptation through community selection? What community adaptations occur under extreme $\mathrm{P}$ limitation and what effect does this have on the stability of soil C stocks?

In the present study, we demonstrate that a reduction in the magnitude of throughfall can profoundly alter microbial communities, resulting in shifts in the abundance and diversity of certain taxa. The throughfall exclusion experiment brought about significant modifications to soil pore water chemistry (notably elevated solute concentrations and reduced water potential) that selected for organisms known to dominate arid and semi-arid environments (for example, Actinomycetes) and possibly changing the competitive dynamics of the ecosystem through expanded niche availability for certain groups (Hutchinson, 1961). Short-term drought within the same plots a year before the onset of this study, has been demonstrated to lower soil respiration (Wood and Silver, 2012) possibly due to the effect of drought on soil micronutrient status. While this data likely reflects the combination of both heterotrophic and autotrophic respiration, the logical next question to ask is whether the phylogenetic changes observed in the present study lead to consequential changes in the functional potential and metabolic activity of organisms present (Carney et al., 2007).

\section{Acknowledgements}

We thank Julian Fourtney and Kristin DeAngelis for assistance in the field, Joern Larsen and April Van Hise for ICP-MS analyses. NOAA Climate and Global Change postdoctoral fellowship to TEW. This work was partially supported by an NSF grant and DOE grants to WLS and by the Laboratory Directed Research and Development Program of Lawrence Berkeley National Laboratory, by the Director, Office of Science, of the US Department of Energy under Contract No. DE-AC02-05CH11231.

\section{References}

Allison SD, McGuire KL, Treseder KK. (2010). Resistance of microbial and soil properties to warming treatment seven years after boreal fire. Soil Biol Biochem 42: 1872-1878.

Bachar A, Al-Ashhadb A, Soares MIM, Sklarz MY, Angel R, Ungar ED et al. (2010). Soil microbial abundance and diversity along a low precipitation gradient. Microb Ecol 60: $453-461$.

Bonebrake TC, Mastrandrea MD. (2010). Tolerance adaptation and precipitation changes complicate latitudinal patterns of climate change impacts. Proc Natl Acad Sci 107: 12581-12586.

Bowen JL, Ward BB, Morrison HG, Hobbie JE, Valiela I, Deegan LA et al. (2011). Microbial community composition in sediments resists perturbation by nutrient enrichment. ISME J 5: 1540-1548.

Bressan M, Mougel C, Dequiedt S, Maron P-A, Lemanceau P, Ranjard L. (2008). Response of soil bacterial community structure to successive perturbations of different types and intensities. Environ Microbiol 10: 2184-2187.

Caporaso J, Kuczynski J, Stombaugh J, Bittinger K, Bushman F, Costello E et al. (2010). QIIME allows analysis of high-throughput community sequencing data. Nat Methods 7: 335-336.

Carbone MS, Still CJ, Ambrose AR, Dawson TE, Williams AP, Boot CM et al. (2011). Seasonal and episodic moisture controls in plant and microbial contributions to soil respiration. Oecologia 167: 265-278.

Carney KM, Hungate BA, Drake BG, Megonigal JP. (2007). Altered soil microbial community at elevated CO2 leads to loss of soil carbon. Proc Natl Acad Sci 104: 4990-4995.

Chacon N, Silver WL, Dubinsky EA, Cusack DF. (2006). Iron reduction and soil phosphorus solubilization in humid tropical forest soils: the role of labile carbon pools and electron shuttle compound. Biogeochemistry 78: $67-84$.

Chaer G, Fernandes M, Myrold D, Bottomley P. (2009). Comparative resistance and resilience of soil microbial communities and enzyme activities in adjacent native forest and agricultural soils. Microbial Ecol 58: 414-424.

Chanal A, Chapon V, Benzerara K, Barakat M, Christen R, Achouak W et al. (2006). The desert of Tataouine: an extreme environment that hosts a wide diversity of microorganisms and radiotolerant bacteria. Environ Microbiol 8: 514-525.

Chowdhury N, Marschner P, Burns RG. (2011). Soil microbial activity and community composition: 
Impacts of changes in matric and osmotic potential. Soil Biol Biochem 43: 1226-1236.

Cleveland CC, Reed SC, Townsend AR. (2006). Nutrient regulation of organic matter decomposition in a tropical rain forest. Ecology 87: 492-503.

Cleveland CC, Wieder WR, Reed SC, Townsend AR. (2010). Experimental drought in a tropical rain forest increase soil carbon dioxide losses to the atmosphere. Ecology 91: 2313-2323.

Davet P. (2004). Microbial Ecology of the Soil and Plant Growth. Enfield Science Publishers: New Hampshire.

Davidson EA, Ishida FY, Nepstad DC. (2004). Effects of an experimental drought on soil emissions of carbon dioxide, methane, nitrous oxide and nitric oxide in a moist tropical forest. Glob Change Biol 10: 718-730.

Davidson EA, Nepstad DC, Ishida FY, Brando PM. (2008). Effects of an experimental drought and recovery on soil emissions of carbon dioxide, methane, nitrous ocide, and nitric oxide in a moist tropical forest. Glob Change Biol 14: 2582-2590.

DeAngelis KM, Silver WL, Thompson AW, Firestone MK. (2011). Microbial communities acclimate to recurring changes in soil redox potential status. Environ Microbiol 12: 3137-3149.

Deutsch CA, Tewksbury JJ, Huey RB, Sheldon KS, Ghalambor CK, Haak DC et al. (2008). Impacts of climate warming on terrestrial ectotherms across latitude. Proc Natl Acad Sci 105: 6668-6672.

Draper NR, Smith H. (1998). Applied Regression Analysis. Wiley-Interscience: Hoboken, NJ, pp 307-312.

Drees KP, Neilson JW, Betancourt JL, Quade J, Henderson DA, Pryor BM et al. (2006). Bacterial community structure in the hyperarid core of the Atacama Desert, Chile. Appl Environ Microbiol 72: 7902-7908.

Dubinsky EA, Silver WL, Firestone MK. (2010). Tropical forest soil microbial communities couple iron and carbon biogeochemistry. Ecology 91: 2604-2612.

Easterling DR, Meehl GA, Parmesan C, Changnon SA, Karl TR, Mearns LO. (2000). Climate extremes: observations, modeling, and impacts. Science 289: 2068-2074.

Evans SE, Wallenstein MD. (2011). Soil microbial community response to drying and rewetting stress: does historical precipitation regime matter? Biogeochemistry 109: 101-116.

Fierer N, Schimel JP, Holden PA. (2003). Influence of drying-rewetting frequency on soil bacterial community structure. Microbial Ecol 45: 63-71.

Fuerst JA, Sagulenko E. (2011). Beyond the bacterium: planctomycetes challenge our concepts of microbial structure and function. Nat Rev Microbiol 9: 403-413.

Giorgi F, Bi X. (2005). Updated regional precipitation and temperature changes for the $21^{\text {st }}$ century from ensembles of recent AOGCM simulations. Geophys Res Lett 32: L21715.

Goodfellow M, Williams S. (1983). Ecology of actinomycetes. Annu Rev Microbiol 37: 189-216.

Grace J, Malhi Y, Higuchi N, Meir P. (2001). Productivity and carbon fluxes of tropical rain forests. In: Roy J, Saugier B, Mooney HA (eds). Terrestrial Global Productivity. pp 401-426.

Holtgrieve G, Jewett P, Matson P. (2006). Variations in soil $\mathrm{N}$ cycling an trace gas emissions in wet tropical forests. Oecologia 146: 584-594.

Hueso S, García C, Hernández T. (2012). Severe drought conditions modify the microbial community structure, size and activity in amended and unamended soils. Soil Biol Biochem 50: 167-173.

Huey RB, Deutsch CA, Tewksbury JJ, Vitt LJ, Hertz PE, Alvarez Perez HJ et al. (2009). Why tropical forest lizards are vulnerable to climate warming. Proceedings of the Royal Society B: Biological Sciences 276: 1939-1949.

Hutchinson GE. (1961). The paradox of the plankton. Am Nat 95: 137-145.

Ivanov II, Atarashi K, Manel N, Brodie EL, Shima T, Karaoz U et al. (2009). Induction of intestinal TH17 cells by segmented filamentous bacteria. Cell 139: 485-498.

Jobbágy EG, Jackson RB. (2000). The vertical distribution of soil organic carbon and its relation to climate and vegetation. Ecol Appl 10: 423-436.

Jones SE, Lennon JT. (2010). Dormancy contributes to the maintenance of microbial diversity. Proc Natl Acad Sci 107: 5881-5886.

Klevenskaya IL. (1960). Growth of soil actinomycetes in media of varying osmotic pressure. Mikrobiologia 29: 161-164.

Landesman WJ, Digton J. (2010). Response of soil microbial communities and the production of plant-available nitrogen to a two-year rainfall manipulation in the New Jersey Pinelands. Soil Biol Biochem 42: 1751-1758.

Leibler S, Kussell E. (2010). Individual histories and selection in heterogenous populations. Proc Natl Acad Sci 107: 13183-13188.

Liptzin D, Silver WL. (2009). Effects of carbon additions on iron reduction and phosphorus availability in a humid tropical forest soil. Soil Biol Biochem 41: 1696-1702.

Liptzin D, Silver WL, Detto M. (2011). Temporal dynamics in soil oxygen and greenhouse gases in two humid tropical forests. Ecosystems 14: 171-182.

Meehl GA, Washington WM, Santer BD, Collins WD, Arblaster JM, Aixue $\mathrm{H}$ et al. (2006). Climate change projections for the twenty-first century and climate change commitment in the CCSM3. J Climate 19: 2597-2616.

Metcalfe DB, Meir P, Aragao LEOC, Malhi Y, da Costa ACL, Braga A et al. (2007). Factors controlling spatio-temporal variation in carbon dioxide efflux from surface litter, roots and soil organic matter at four rain forest sites in the eastern Amazon. J Geophys Res 112: GO4001.

Neelin JD, Münnich M, Su H, Meyerson JE, Holloway CE. (2006). Tropical drying tends in global warming models and observations. Proc Natl Acad Sci 103: 6110-6115.

Okoro CK, Brown R, Jones AL, Andrews BA, Aenjo JA, Goodfellow $M$ et al. (2009). Diversity of culturable actinomycetes in hyper-arid soils of the Atacama Desert, Chile. Anton Leeuw 95: 121-133.

Pan Y, Birdsey RA, Fang J, Houghton R, Kauppi P, Kurz WA et al. (2011). A large and persistent carbon sink in the world's forests. Science 333: 988-993.

Pett-Ridge J, Firestone MK. (2005). Redox fluctuation structures microbial community in a wet tropical soil. Appl Environ Microbiol 71: 6998-7007.

Prosser JI, Bohannon BJM, Curtis TP, Ellis RJ, Firestone MK, Freckleton RP et al. (2007). The role of ecological theory in microbial ecology. Nat Rev Microbiol 5: 384-392.

Reed SC, Townsend AR, Taylor PG, Cleveland CC. (2011). Phosphorus cycling in tropical forests growing on highly weathered soils. In: Bünemann E, Oberson A, Frossard E (eds). Phosphorus in Action. Soil Biology. Springer-Verlag: Berlin-Heidelberg.

Ross SM. (1993). Organic matter in tropical soils: current conditions, concerns and prospects for conservation. Prog Phys Geog 17: 265-305. 
Schimel J, Balser TC, Wallenstein M. (2007). Microbial stress-response physiology and its implications for ecosystem function. Ecology 88: 1386-1394.

Schmidt MW, Torn M, Abiven S, Dittmar T, Guggenberger G, Janssens IA et al. (2011). Persistence of soil organic matter as an ecosystem property. Nature 478: 49-56.

Silver WL, Lugo AE, Keller M. (1999). Soil oxygen availability and biogeochemical cycling along elevation and topographic gradients in Puerto Rico. Biogeochemistry 44: 301-328.

Silver WL, Thompson AW, McGroddy ME, Varner RK, Robertson JR, Dias JD et al. (2005). Fine root dynamics and trace gas fluxes in two lowland tropical forest soils. Glob Change Biol 11: 290-306.

Stark J, Firestone MK. (1995). Mechanisms for soil moisture effects on activity of nitrifying bacteria. Appl Environ Microbiol 61: 218-221.

Townsend AR, Cleveland CC, Houlton BZ, Alden CB, White JWC. (2011). Multi-element regulation of the tropical forest carbon cycle. Front Ecol Environ 9: 9-17.

Trenberth KE, Jones PD, Ambenje P, Bojariu R, Easterling D, Klein Tank A et al. (2007). Observations: surface and atmospheric climate change. In: Solomon S, Qin D, Manning M, Chen Z, Marquis M, Averyt KB (eds). Climate Change 2007: The Physical Science Basis. Contribution of Working Group 1 to the Forth Assessment Report of the Intergovernmental Panel on Climate Change. Cambridge University Press: Cambridge, United Kingdom and New York, NY, USA.

Vasconcelos SS, Zarin DJ, Capanu M, Littell R, Davidson EA, Ishida FY et al. (2004). Moisture and substrate availability constrain soil trace gas flux in an eastern
Amazonian regrowth forest. Glob Biogeochem Cycles 18: 10.

Vitousek PM, Howarth RW. (1991). Nitrogen limitation on land and sea: how can it occur? Biogeochemistry 13: 87-115.

Vitousek PM, Sanford RL. (1986). Nutrient cycling in moist tropical forest. Rev Ecol Systemat 17: 137-167.

Walker TW, Syers JK. (1976). The fate of phosphorus during pedogenesis. Geoderma 15: 1-19.

Wallenstein MD, Hall EK. (2012). A trait-based framework for predicting when and where microbial adaptation to climate change will affect ecosystem functioning. Biogeochemistry 109: 35-47.

Welsh DT. (2000). Ecological significance of compatible solute accumulation by micro-organisms: from single cells to global climate. FEMS Microbiol Rev 24: 263-290.

Wertz S, Degrange V, Prosser JL, Poly F, Commeaux C, Guillaumaud N et al. (2007). Decline of soil microbial diversity does not influence the resistance and resilience of key soil microbial functional groups following a model disturbance. Environ Microbiol 9: 2211-2219.

Williams ST, Shameemullah M, Watson ET, Mayfield CI. (1972). Studies on the ecology of Actinomycetes in soil-VI. The influence of moisture tension on growth and survival. Soil Biol Biochem 4: 215-225.

Wood TE, Silver WL. (2012). Strong spatial variability in trace gas dynamics following experimental drought in a humid tropical forest. Glob Biogeochem Cycles 26: 12.

Zak DR, Holmes WE, White DC, Peacock AD, Tilman D. (2003). Plant diversity, soil microbial communities, and ecosystem function: are there any links? Ecology 84: 2042-2050.

Supplementary Information accompanies the paper on The ISME Journal website (http://www.nature.com/ismej) 